\title{
The Contribution of University EFL Instructors in Creating Educational Strategies to Develop Ideological Security at the University of Tabuk within the Saudi Vision 2030
}

\author{
Abdulrahman M. Alfahadi \\ Department of English Languages and Translation, Faculty of Education and Arts, University of Tabuk, Tabuk, Kingdom of Saudi \\ Arabia
}

Corresponding Author: Abdurrahman M. Alfahadi, E-mail: aalfahadi@ut.edu.sa

ARTICLE INFORMATION

Received: November 14, 2020

Accepted: December 18, 2020

Volume: 3

Issue: 12

DOI: $10.32996 /$ ijllt.2020.3.12.18

\section{KEYWORDS}

Educational Strategies, Ideological

Security, Globalization, EFL

Instructors, Vision 2030

\section{ABSTRACT}

This study aimed at examining the contribution of university EFL instructor in creating educational strategies to develop ideological security at the University of Tabuk (UT) within the Saudi Vision for the academic year 2020. This mixed-mode research included $60 \mathrm{EFL}$ instructors who were selected randomly from the Institute of Languages (IL) at UT in Saudi Arabia. It is based on the general theory of security and modern theories of the analysis of social phenomena (Fairclough, 2003). The researcher implemented two research instruments to elicit data from the participants are; questionnaires and a semi-structured interview. The analysis was done quantitatively and qualitatively using statistical (SPSS; Version 24.0) and thematic analysis. The results revealed that EFL instructors have a great and in-depth contribution to creating educational strategies in developing ideological security based on 2030 Vision. 64\% of the participants indicated that existing educational strategies implemented by EFL instructors for developing ideological security amongst learners. $87 \%$ of them pointed out that creating educational strategies affect developing ideological security at UT. Whilst $86 \%$ of them said that UT EFL instructors support the idea of ideological security and globalization within the Campus. Also, the qualitative findings indicated that the contribution of university EFL instructors in creating educational strategies to develop ideological security at UT within the Saudi Vision 2030 was very effective and strengthened learners' belief in national identity. Additionally, the results indicated that EFL instructors' awareness concerning developing ideological security was acceptable and showed high agreement towards the creation of educational strategies. This study recommends that further research be carried out on this concern.

\section{Introduction}

The concept of ideology took the attention of researcher and scholar a long time ago. It relates to the ability of an individual to accept the reality of the external world. Such a concept developed to be the focus of many empirical studies lately (Tu, 2019). Ideology as a novel thought refers to the depictions of features of the world that can be revealed to affect creating, holding and shifting cultural associations of supremacy, dominance and manipulation (Fairclough, 2003). Relatively, ideologies are undervalued as common improvements of social representativeness. The point is that such improvements will often grow to be reified and reserved as absolute truth (Abu Shareikh, 2014). Besides the idea of ideology, security in its widest significance holds social rights, virtuous governance, educational privileges, health care and medicinal services and ensures that each person shares overtures and choices to select their own prospective freedom (Liu, 2015). Examining ideological security subject at this time is important axes. It is one of the most significant fields to be argued as a distinct matter in scientific research. The constituent of ideological security is substantial in all aspect of human life. Noting that, ideological security developed to be a definite necessity for every social community to attain psychological steadiness and a sense of balance to defend its intellectual views and cultural heritages from external influences. This displays that ideological security is necessitated at presently (Nardina, 2008).

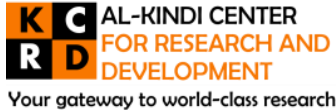

Your gateway to world-class research
Published by Al-KindiCenter for Research and Development. Copyright (c) the author(s). This is an open access article under CC BY license (https://creativecommons.org/licenses/by/4.0/) 
Ideological security has shown to be a legal need nowadays for every social member. This is because ideological security is the protection regulator within the severe contemporary circumstances of ferocity and terrorism that intimidate the humblest humanitarian rights. Since it is the concern of every person, attaining ideological security is necessary for everyone in society. This is not to be included and affected by offensive beliefs (Wang, 2013). Therefore, the realization of ideological security is a national responsibility and one of the most indispensable encounters that the third world nations experience within the corresponding assertions of globalization. This comprises the political, economic and social encounters. So, the global changes resulted in the rise of many radical fluctuations in the patterns of philosophy that a society practices across borders, locally and globally (Long, 2002).

Globalization caused the presence of a lot of threats and claims that portend the ideological security of every society. However, the realization of ideological security is a political claim for politicians and indispensable for social and educational establishments comprising schools, colleges, and universities (Al-Saadiya, 2008). Educational foundations are amid these social organizations that should consider the achievement of ideological security as primacy and national responsibility. This is because of their excessive influence in making and creating virtuous inhabitants able to distinguish effects. In this respect, main universities should keep youths away from external offensive or deviant beliefs to attain ideological security in this respect. The university is one of the constructs liable for structuring individuals' personalities and empowering them with compulsory awareness to encounter security stresses by bearing in mind social and moral ideologies as educational fundamentals connected to ideological security. Additionally, nurturing learners on nation's love and loyalty where an instructor is the main concern in realizing this noble objective (Nakpodia, 2010).

An instructor is the means of success to naturalize social actions and correct most social ideas in most cultures worldwide. He/she is the one who shoulders the restraint of defending the new generation from becoming included in terroristic thoughts and actions by inspiring the language of disputes amongst learners and overlay the way for them to show their thinking and views in diverse manners in wide-ranging social activities and settings. This is to correct the learners' unacceptable behaviours and hold them away from external influences and teach them the spirit and love of nation as a way of achieving ideological security (Guzzetti \& William, 2004). Thus, security, safety and educational strategies constitute key areas of human concern and stability.

Therefore, it moves without saying that it is the most applicable time to study ideological security at a tertiary education level, particularly in a Saudi context. To this end, it is viewed as a significant area, imposing substance attention to be shown in this concern. Of identical implication to this study, it is explained the significance of concentrating on the motivation and the necessity for ideological security, and how individuals and desires interchangeably influence each other. There is no uncertainty that ideological security attains stability and psychological balance and secures individuals' intellectual and cultural beliefs and heritage from irregular effects and ideologies. Hence, the necessity for ideological security has developed one of the most significant necessities of the present time. Ideological security, nowadays, is a sincere necessity for all individuals and societies, as it is a safety valve against the violence, terrorism and manipulation of the intellectual beliefs of young people, as observed in societies.

According to Al-Saadiya (2008), nowadays, it is overbearing to evade all efforts to be knotted in this web of deviant thoughts. The instructors constitute the support upon which rest the universities' objectives of structuring the learners' character, assessing their behaviour, and shaping their views. The instructor is almost constantly the positive and prime technique for keeping the learners' course of ideology on the correct pathway and correcting their insights and ideas. Therefore, their involvement comes in upholding ideological security and lecturing the relevant nonconformities to which learners may be unprotected in light of present critical encounters of globalization (Alfahadi, 2017).

\section{Literature Review}

Lately, many attempts have given enough concern to the study of the connection between educational strategies and the development of ideological security. This might relate to the importance of this educational aspect to obtain confidence in language instructors and their role in the classroom setting.

Yang and Cao (2019) stated that the features of the new media age of the network examine the unavoidability of the integration of network new media and college students' ideological and political education and provide the fusion path of network new media and college students' ideological and political education.

Also, Yang (2019) investigated college students' network ideological and political education from the perspective of cultural selfconfidence. The study was conducted in China in a number of colleges and universities. It indicated a series of countermeasures that help strengthen the creation of network education platform as well as strengthen the supervision of network information and inspire the content of educational ideological network. Also, it gave some reference for the cultivation of college learners' educational self-confidence consciousness besides the tendency of developing network ideological and educational network. 
Further, Yi and Dan (2020) examined the realization of ideological and political education in college English based on cultural confidence in China. The findings of the study showed that the present educational ideology in china has a great practical significance of cultivating learners' cultural self-confidence through syllabus setting. Also, the results showed that ideology possesses the power to examine the significance between college English curriculum setting and ideological and political education that suggests a route planning for improving the relevance.

Additionally, Li and Fu (2020) studied college English teaching based on the concept of ideological and political education in all courses. The study was conducted at Chinese colleges and universities in the Shanghai region in 2016. The results concluded that they are many effective ways that help to integrate ideological and political theory teaching into college English course from the perspectives of teachers, students, teaching systems, teaching contents and models of evaluation.

In the researcher's view, understanding the contribution of University EFL instructors in creating educational strategies to develop ideological security is of great significance. This is because their knowledge and acquaintance to ideological security in educational security has become a necessity to be perceived within the realm of global changes (Alfahadi, 2017). Instructors teaching English as a foreign language encounter many problems when it comes to achieving ideological security for their students, specifically through creating educational strategies in a classroom setting. So, this study is an attempt to examine the contribution of university EFL instructors in creating educational strategies to develop ideological security at the University of Tabuk within the Saudi Vision 2030, since it has not been investigated earlier.

\section{The Study Problem}

Current trends and changes in the era of information technology put instructors in the wave of many problems and difficulties that restricted them from creating educational strategies to obtain ideological security, a particularly tertiary education level (Zhou, 2019). This led to a rich setting for intellectual colonization and threatened the cultural steadiness and national identity and facilitated increasing terroristic thoughts that defy national unity. One of the difficulties that encounter EFL instructors' act of reaching ideological security is globalization and its rights, such as social media, networks and the internet. These assertions can result in the appearance of many risks such as violence, terrorism, corruption, loneliness, addiction, pornography and behavioural deterioration. Notwithstanding the significance of educational strategies and ideological security, none of the aforementioned studies has examined this problem.

\section{Objectives of the Study}

This study intends to achieve the following research objectives:

i. To examine the existing educational strategies implemented by EFL instructors for developing ideological security amongst learners at the University of Tabuk.

ii. To investigate the extent in which creating educational strategies affect developing ideological security at UT in Saudi Arabia.

iii. To find out whether UT EFL instructors support the idea of ideological security and globalization within the Campus.

\section{Study Questions}

In order to achieve the research objectives, this study addresses the following research questions:

i. What are the existing educational strategies implemented by EFL instructors for developing ideological security amongst learners at the University of Tabuk?

ii. To what extent does creating educational strategies affect the development of ideological security at UT in Saudi Arabia?

iii. To what extent do UT EFL instructors support the idea of ideological security and globalization within the Campus?

\section{The Significance of the Study}

This study is significant for helping EFL instructors at the Institute of Languages at UT realize their role in creating educational strategies to develop ideological security in Saudi Arabia, where the Arab region experiences violence and uncertainty. Also, it is useful for its timing as a reaction for most of the political, educational and cultural concerns worldwide that necessitates a systematic consideration of ideological security as related to EFL instructors' cultural background to attain national stability, particularly within 2030 vision. Further, this research is essential for being an attempt to establish an image to aid EFL instructors at the tertiary education level create educational strategies to develop ideological security in Saudi universities.

\section{Methods and Materials}

To achieve the research objectives, this research adopted the descriptive-analytical approach. $60 \mathrm{EFL}$ instructors from the Institute of Languages at UT were randomly chosen to participate in the study. The study was conducted in the academic year 2020. Participants in the study majored in TESOL, EFL teachers, Linguistic and Education. This qualitative-quantitative study used two 
research instruments to collect data from the participants are; questionnaires and semi-structured interviews. It analysed data using both statistical analysis (SPSS; Version 24.0) and thematic analysis procedures.

\section{Results}

The data of the study were collected from $60 \mathrm{EFL}$ instructors from the Institute of Languages at UT. The analysis of the data was done quantitatively and qualitatively. The researcher analysed and counted the frequencies and percentages of the EFL instructors' responses to the questionnaires to address research the first research question. This was performed by using SPSS (version 24.0) and descriptive statistics to identify and present the frequency participants' responses. Figure 1.1 in the next section depicts the existing educational strategies implemented by EFL instructors for developing ideological security amongst learners at UT.

Figure 1.1: The Existing Educational Strategies Implemented by EFL Instructors for Developing Ideological Security amongst Learners at the University of Tabuk.

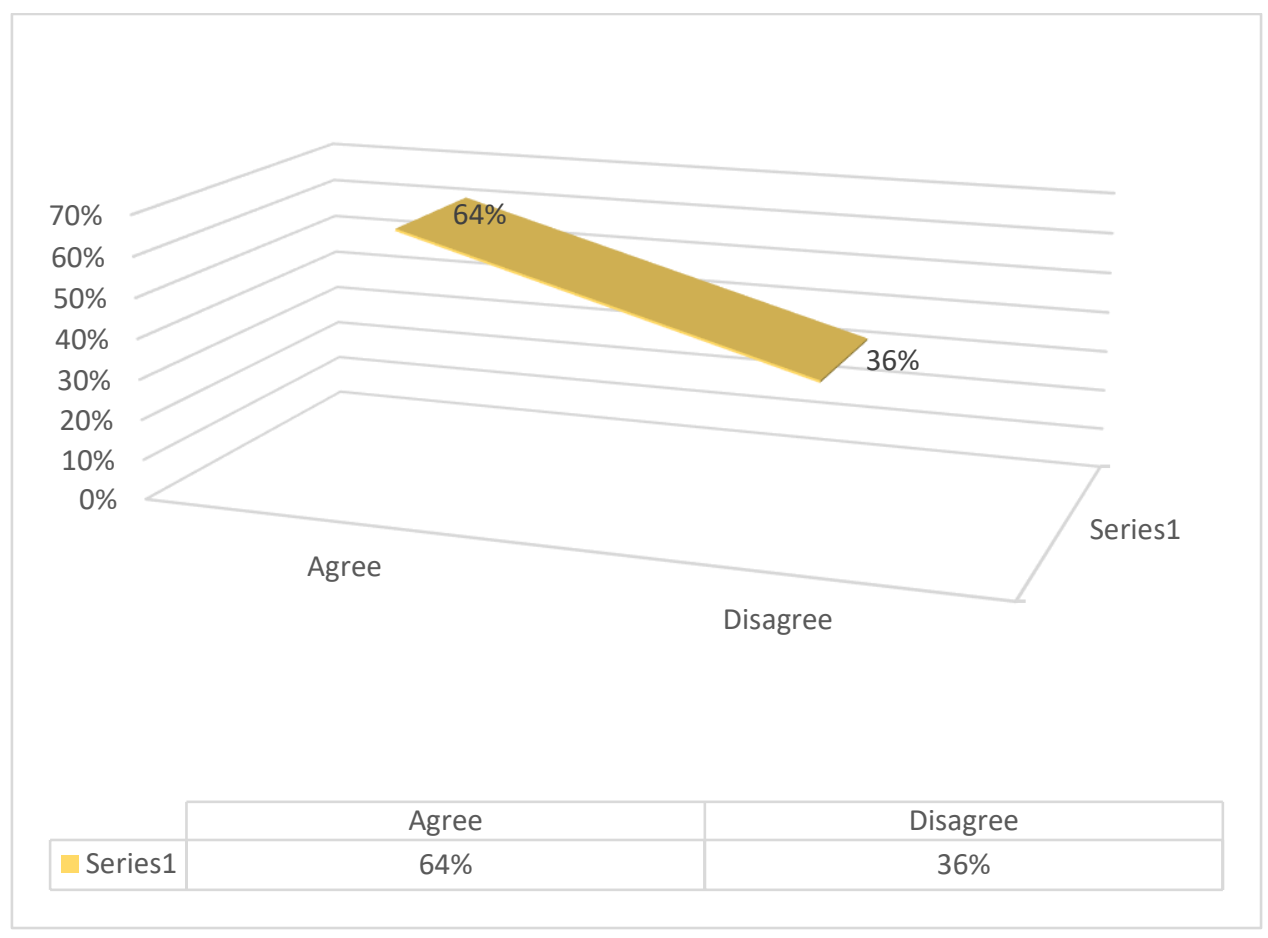

Based on Figure 1.1 reveals that $64 \%$ of them agreed that the educational strategies that they use in achieving ideological security were effective, whilst $36 \%$ of them said they were ineffective when asked about the existing educational strategies implemented by EFL instructors for developing ideological security amongst learners at the University of Tabuk. However, Figure 1.2 addressed the second research question as $87 \%$ stated that creating educational strategies affect developing ideological security at the Institute of Languages at UT. Whilst, $12 \%$ pointed out that creating educational strategies do not affect developing ideological security. Table 1.2 presents how creating educational strategies affect developing ideological security at UT in Saudi Arabia. Additionally, Figure 1.2 shows that $86 \%$ of UT EFL instructors support the idea of ideological security and globalization within the campus and $14 \%$ of them do not.

Figure 1.2: The Extent in which Creating Educational Strategies Affect Developing Ideological Security at UT in Saudi Arabia. 


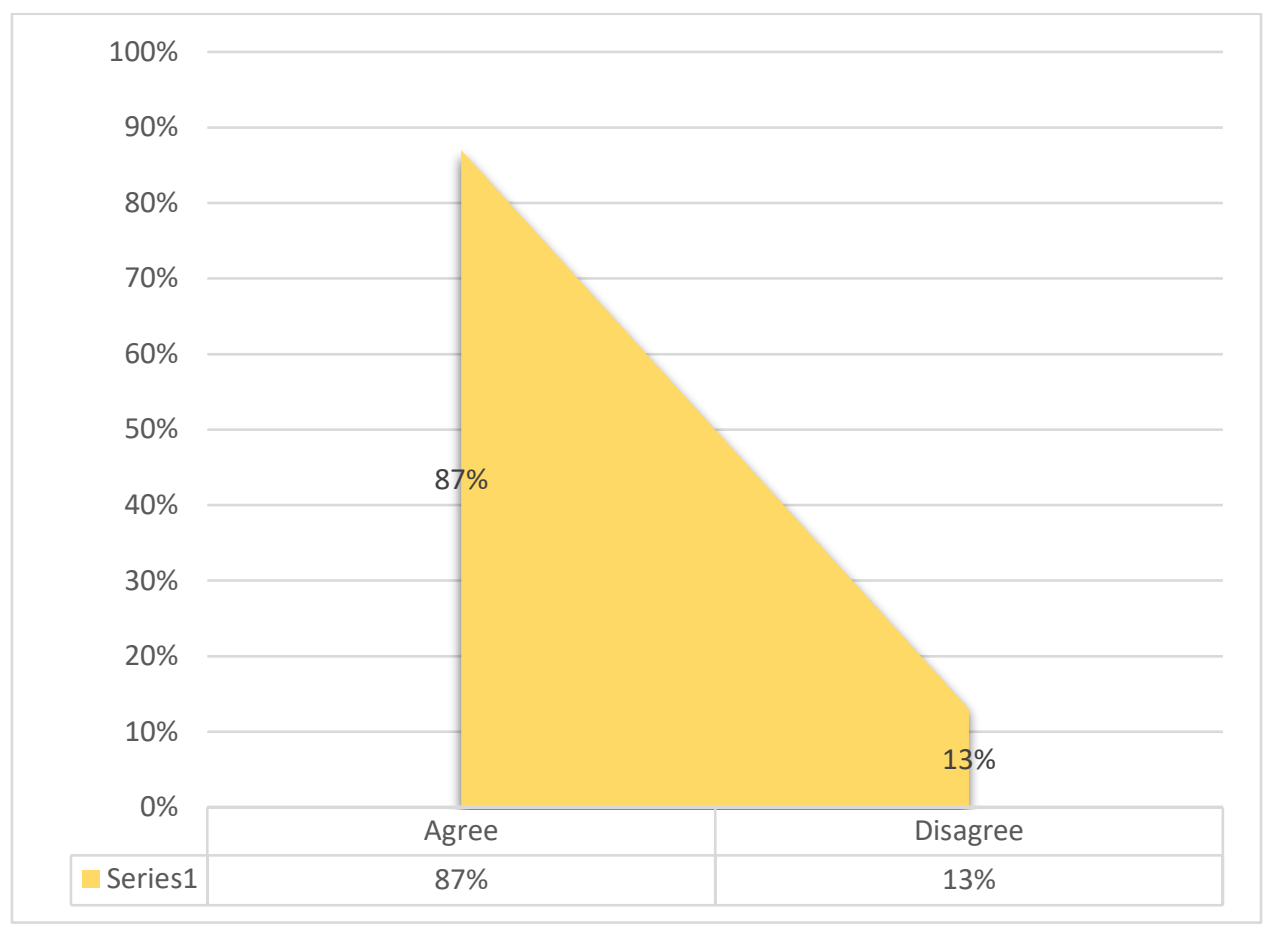

Also, Figure 1.3 below reveals that $86 \%$ of UT EFL instructors support the idea of ideological security and globalization within the campus and $14 \%$ of them do not, as depicted.

Figure 1.3: $\quad$ UT EFL Instructors Support the Idea of Ideological Security and Globalization within the Campus

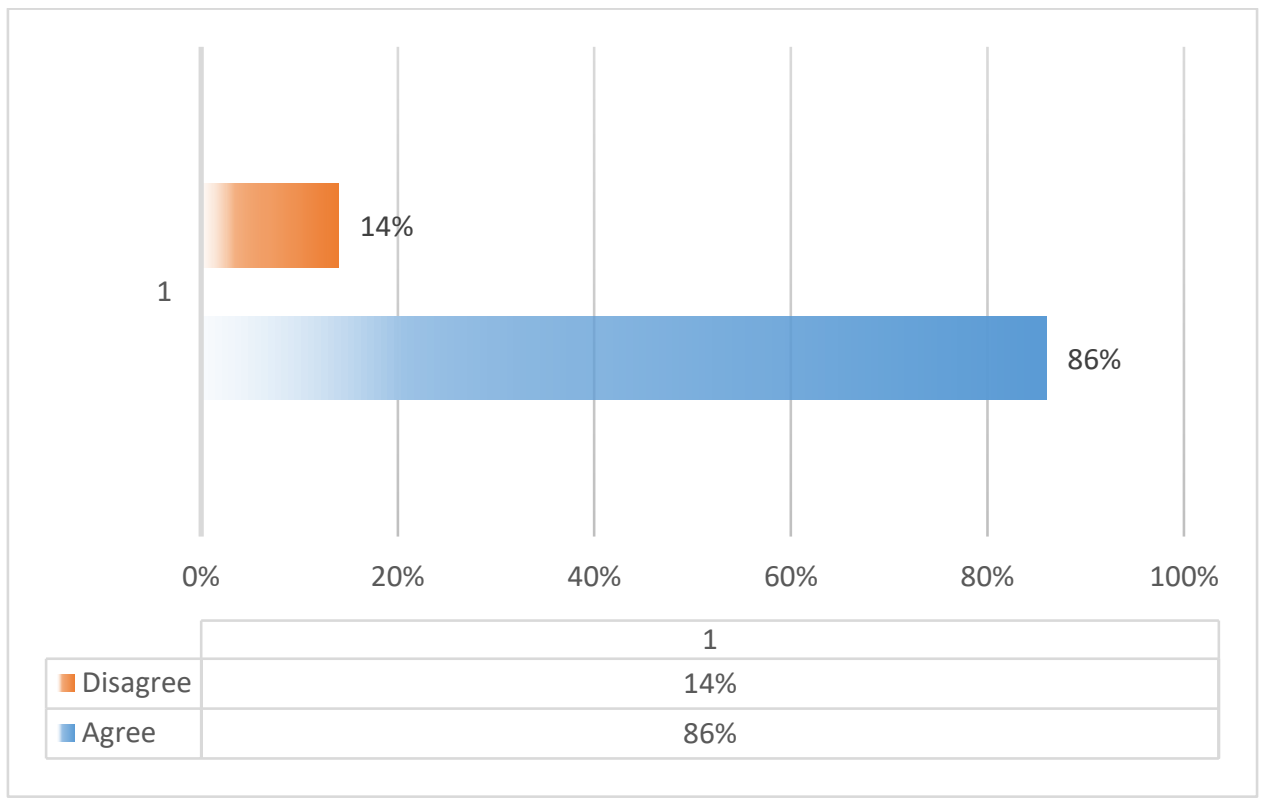

To conclude, the study's quantitative findings showed that $64 \%$ of the participants indicated that existing educational strategies implemented by EFL instructors for developing ideological security amongst learners. Furthermore, $87 \%$ of them pointed out that creating educational strategies affect developing ideological security at UT. Whilst $86 \%$ of them said that UT EFL instructors support the idea of ideological security and globalization within the Campus. Qualitatively, the interview analysis revealed that the contribution of university EFL instructors in creating educational strategies to develop ideological security at UT within the Saudi Vision 2030 was very effective and strengthened learners' belief in national identity. Additionally, the results indicated that EFL instructors' awareness concerning developing ideological security was acceptable and showed high agreement towards the creation of educational strategies. 


\section{Discussion}

Having reviewed the results of the findings past research, it is observed that EFL instructors should raise the awareness of their learners concerning developing the concept of ideological security as related to the present global trends and change. This study highpoints the significant contribution of EFL instructors in fostering ideological security's concept amongst learners. Also, it focuses on the authenticity of the strategies used by EFL instructors at UT thereof. To this conclusion, this research proposes an even better insistence. Through the viewpoints of EFL instructors throughout the exploration of the study techniques and percentages of the three extents of the research, it has been observed that the idea of endorsing ideological security is being put to practice, and there is a significant influence for the EFL instructors in this regard. Therefore, EFL instructors should be more competent as to improve their role. The latter involves supporting the ideological security idea to their learners and increasing learners' insights and ideas, which may then challenge their intellectual views and thoughts. The extent of the dynamics stated herein functions side by side with the multitude of conflicts adjacent to us, and the ideological operations targeting young generations in Saudi Arabia are reflected in 2030 vision.

\section{Conclusion}

The generalization of the results of the study based on the responses of the $60 \mathrm{EFL}$ instructors at the Institute of Languages at UT might be limited to a group of instructors at the University of Tabuk with similar characteristics only. Therefore, it might not be generalized to other populations with distinctive cultural backgrounds. Concerning the sample of the study and number of EFL instructors joining in this research was actually small and abide by one closely related discipline, English as a foreign language.

Therefore, to achieve more valid and consistent results, bigger groups of participants throughout different majors and specializations should be examined except the one included in this study. Another limitation is that data collected through qualitative interviews and quantitative questionnaires can merely give general patterns of the role of university's instructors in creating educational strategies to develop ideological security at UT within the umbrella of 2030 vision for the academic year 2020 , withdrawing the bases of their contribution and what led them to propose about the way they act. Additionally, the survey barely discussed all the related factors included in these issues, though important and inspiring details were not explored. More perceptions into other national universities instructors' role ought to be examined and interviewed with regard to this aspect. Also, this study should be replicated on a larger number of participants, including learners of varied fields nationwide. Related variables that can influence the role of university EFL instructors have to be the target of further investigations.

Moreover, authenticity proposes that the opinions of tertiary education EFL instructors might not relate to one another. Thus, there is a necessity to carry out future investigations on different disciplinary instructors' beliefs, attitudes and readiness to contrast with those of their instructors in, unlike local universities. It would show a comprehensive depiction of the setting and, therefore, support connecting the inconsistencies in their opinions. Also, it may be useful to test more how to exploit the involvement of university instructors in generating educational strategies to improve ideological security to support learners more in their educational setting. To conclude, this study recommends; a) developing the number of disciplines connected to qualifying instructors towards their involvement in supporting ideological security; b) crafting educational strategies that upkeep the influence of instructors in improving the ideological security concept; c) proposing original research to examine thorough issues associated with endorsing ideological security concept amongst learners; d) conducting consistent workshops for learners to endorse ideological security concept; and e) raising learners 'awareness to the approaches of intellectual invasion, which plague the global era.

\section{References}

[1] Abu Shareikh, S (2014). Towards a Proposed Strategy for the Prevention of Intellectual Security Threats in the Islamic Culture Course in the Light of the Security Needs of Students. Journal of the Union of Arab Universities for Research in Higher Education, 34(1).

[2] Alfahadi, M. (2018). The contribution of university teachers in creating educational strategies to develop intellectual security in Saudi Arabia academic year 2018: Case study (Tabuk University). British Journal of Humanities and Social sciences, VOL.21.

[3] Al-Saadiya. A. (2008). The Contribution of Education in Reinforcing Intellectual Security: The Message of Education, Sultanate of Oman. 19124.

[4] Fairclough, N. (2003). Analysing discourse: Textual analysis for social research. Psychology Press.

[5] Guzzetti, J., \& William, Wayne. (2004). Examining Intellectual Safety in The seine Classroom. Journal of Research in Science Teaching, 33(1)

[6] Li, F. and Fu, H. (2020). Study on College English Teaching Based on the Concept of Ideological and Political Education in All Courses. Creative Education, 11, 997-1007. doi: 10.4236/ce.2020.117072.

[7] Long, A. (2002). Globalization and its Challenges for Theological Education. Available at: http: / /www.iie.com /Fischer/pdf/fisher 011903.

[8] Nardina, O. V. (2008). Counterterrorism in the Russian Federation: the formation of ideological and moral immunity from violence. Ekonomika polprivrede LIV (5-6), 22-27.

[9] Nakpodia, E. D. (2010). Culture and curriculum development in Nigerian Schools, African Journal of History and Culture (AJHC), 2 (1), 1-9.

[10] Tu Y.L. (2019). Research on College Students' Network Ideological and Political Education under the New Normal State, Way to Success, 21 (06), 15. 
[11] Yang B.J., Cao S.L. (2019). Integrative development of network new media and ideological and political education of college students, Communication World, 26(7), 369-370.

[12] Yang Jianhua. (2019). Research on College Students' Network Ideological and Political Education from the Perspective of Cultural Selfconfidence. Francis Academic Press, UK. 2019 International Conference on Reform, Technology, Psychology in Education (ICRTPE 2019). DOI: 10.25236/icrtpe.

[13] Yi, Y., \& Dan, W. (2020). The Realization of Ideological and Political Education in College English Based on Cultural Confidence. Creative Education, 11, 2193-2198.

[14] Wang, S. (2013, July). On the Self-consciousness of Cultural Security of Ideological and Political Education in College. In International Conference on Computer, Networks and Communication Engineering (ICCNCE 2013) (pp. 316-319). Atlantis Press.

[15] Z. Liu. (2015). the Influence and Countermeasures of the Social Ideological Trend on the Campus Security and Stability from the Adolescent Perspective, in 2nd International Symposium on Engineering Technology, Education and Management, pp. 1084-88.

[16] Zhou W.R. (2019). Research on Ideological and Political Education of College Students from the Perspective of Cultural Self-confidence, Journal of Huainan Vocational and Technical College, 19(1), 21-22. 